\title{
A Clinco-Bacteriological Study of Leprosy in Paediatric Age Group *\#
}

\author{
Leena Das ${ }^{1}$, Bijay Kumar Meher ${ }^{1}$, Nikunja Bihari Das ${ }^{2}$, Deepti Damayanty $\operatorname{Pradhan}^{1}$, S. Pradeep ${ }^{1}$, \\ Jayashree Mohanty ${ }^{3}$ \\ ${ }^{1}$ Department of Paediatrics, S.V.P. Post Graduate Institute of Paediatrics, SCBMCH, Cuttack, India; ${ }^{2}$ Pediatric Specialist, Commu- \\ nity Health Centre (CHC), Chikiti, Ganjam, India; ${ }^{3}$ Department of Dermatology, S.C.B. Medical College, Cuttack, India. \\ Email: bkmeher187@yahoo.co.in
}

Received October $23^{\text {rd }}, 2013$; revised November $23^{\text {rd }}, 2013$; accepted November $30^{\text {th }}, 2013$

Copyright (C) 2013 Leena Das et al. This is an open access article distributed under the Creative Commons Attribution License, which permits unrestricted use, distribution, and reproduction in any medium, provided the original work is properly cited.

\begin{abstract}
Clinico-bacteriological study was done in 51 leprosy patients below 14 years of age. Majority of the patients were males in the age group of $11-14$ years. Nearly $84 \%$ had not received any prior treatment because of lack of awareness and financial constraints. Only $11.76 \%$ had a positive contact history. Skin lesions were present in all cases and $84.3 \%$ had lesions mainly on the exposed areas of the body and their number was found to increase significantly with advancing age $(p<0.005)$. These lesions were hypo-pigmented patches in $88 \%$ cases. $88 \%$ of cases had hypo-anesthesia and nerve thickening was observed in $24 \%$ cases. The most common type of skin lesion was borderline tuberculoid (BT) in 53\% cases. Positivity of the skin smears increased significantly as the number of the skin lesions per patient increased $(p<$ 0.001). Multibacillary cases were seen in $15.6 \%$ of cases and found only in the age group of $10-14$ years of age. No statistically significant association between BCG vaccination and prevention of leprosy was seen.
\end{abstract}

Keywords: Leprosy in Children; Tuberculoid Leprosy; BCG

\section{Introduction}

Leprosy is probably the oldest disease known to mankind. It is a chronic infectious disease caused by Mycobacterium leprae. It is one of the leading causes of physical disabilities which contribute to intense social stigma, resulting in discrimination of the patient and their families. According to world statistics at the beginning of 2006, the number of leprosy cases in the world was 22 million. Today the highest burden of cases of world is concentrated in 6 countries and India remains at the top [1]. India accounts for $55 \%$ of the new leprosy cases detected globally in 2010 [2]. According to the National Leprosy Elimination Programme (NLEP) report of March 2012, there were a total of about 0.13 million cases of leprosy in India, $9.7 \%$ of which were children. In Odisha, the prevalence rate (PR) of childhood leprosy is 1.06/10,000 population [3]. The profile and magnitude of leprosy in pediatric populations have an important bearing on the epide-

\footnotetext{
${ }^{*}$ Conflict of interest: none.
}

"Funding: none. miology of the disease and reflect the level of control in a community. A high child proportion signifies active and recent transmission of the disease, making it a robust epidemiological indicator to assess the progress of leprosy control programmes. It is expected to fall towards the elimination phase of a leprosy control programme, suggesting a decrease in transmission levels [4]. A multistage cluster sampling survey in north Bangladesh demonstrated that the prevalence of previously undiagnosed leprosy in children (5 - 14 years old) was 8.6 per 10,000 [5]. In the pediatric age group, leprosy often presents as a single hypopigmented patch, which may or may not be anesthetic, and hence it is confused with other dermatological ailments [6]. With this background, we carried out this present work to study the clinico-bacteriological status of leprosy patients under 14 years of age.

\section{Objective}

- Assessment of the Clinico-bacteriological status of childhood leprosy patients at a tertiary level hospital.

- Smear positivity status in BCG vaccinated children. 


\section{Materials and Methods}

This study was carried out in the out-patient, in the department at Skin \& V.D., S.C.B Medical College and Hospital, Cuttack, Odisha. Fifty one patients under 14 year of age were studied. In each case clinical history, physical examination like type of lesion, distribution, number, colors of lesion and deformities were observed, peripheral nerves cutaneous sensation were examined. Disability assessment and grading were done as per WHO classification [7]. Skin smear examination, Skin biopsy was done in all cases.

Skin Smear Examination: In all patients with skin lesions, smear were taken from 3 sites i.e. one from ear lobe and two from skin and stained by standard technique as out lined by Jopling. The density of bacilli in the smear was recorded using Ridley's logarithmic scale [7].

Skin biopsy: In cases in whom the diagnosis was suspected but was not definite on clinical grounds, biopsy for histological confirmation were done and classification was done by the standard technique [7]. Based on these observations, patients were grouped under five heads as suggested by Indian Association of Leprologist, Indeterminant (I), tuberculoid (TT), borderline (BB), Lepromatous (LL), and pure neuritic (P). The borderline group was further subdivided into borderline tuberculoid (BT), borderline-borderline (BB), borderline lepromatous (BL) sub-groups [8].

\section{Results}

A total of 51 case $\leq 14$ years were studied. About three fourth of cases were males. $58.82 \%$ of cases fell in the age group of $11-14$ yrs. Majority of the children $(56.8 \%)$ has been brought to the hospital between $6-12$ months of onset of lesion. Eighty eight percent had an asymmetrical distribution of skin lesion (Figure 1) while rest had symmetrical skin lesion. In our study single hypo pigmented skin lesion were observed in $60.78 \%$ (Table 1). In $84 \%$ cases had initial skin lesion over the exposed part of the body. Most of children (84\%) had not received any treatment. Only $12 \%$ of the children had positive contact history. Skin sensation was unaffected in only $8 \%$ cases. Examination of nerves revealed that $27.45 \%$ cases had thickened nerves and the commonest nerve involved were ulnar nerve followed by lateral popliteal nerve. As shown in Table 1, there was an increase in number of skin lesion as the age advances $(P<0.005)$.

Based on skin biopsy ppatients were put under different category. 2 cases were tuberculoid (TT) and rests were borderline (BL) cases. Of the border line leprosy, 37 cases were borderline tuberculoid (BT), 4 cases were BTtype-1 reaction, 2 cases were borderline-borderline (BB), 2 cases were borderline lepromatous (BL), 4 cases were BL-type-2 reaction. None of the cases were pure neuritic,
Table 1. Number of skin lesions in various age groups (N 51).

\begin{tabular}{ccccc}
\hline Age (in yrs) & $\mathbf{1}$ & $\mathbf{2}-\mathbf{1 0}$ & $\mathbf{> 1 0}$ & Total \\
\hline $\mathbf{1 ~ - ~}$ & 1.9 & 0 & 0 & 1.9 \\
$\mathbf{6}-\mathbf{1 0}$ & 35.3 & 0 & 3.9 & 39.2 \\
$\mathbf{1 1} \mathbf{- 1 4}$ & 23.5 & 19.6 & 15.7 & 58.9 \\
Total & 60.78 & 19.6 & 19.6 & 100 \\
\hline
\end{tabular}

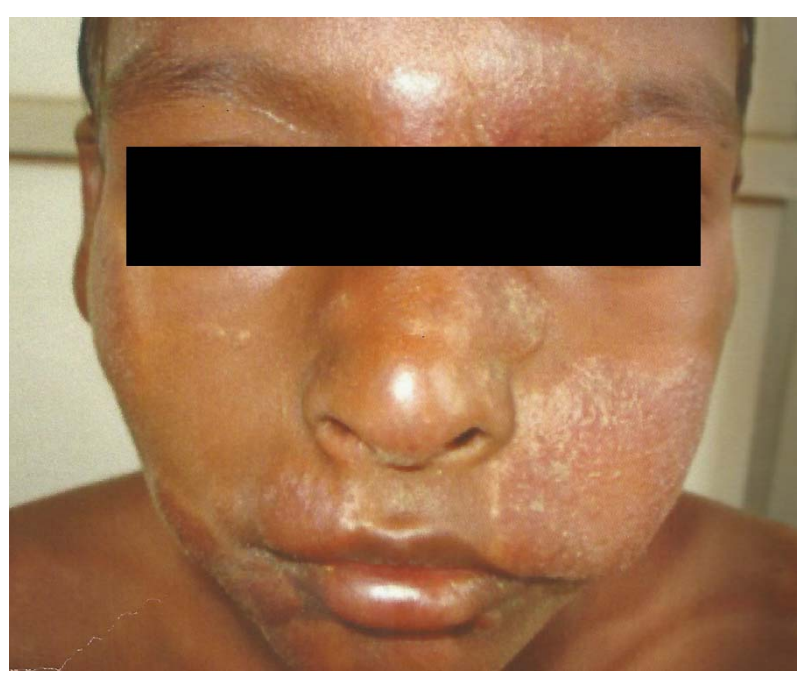

Figure 1. Photograph of 12 yr old male child with large multiple erythematous, infiltered edematous scaly plaques lesions suggestive of Borderline Tuberculoid (BT) Lepra type 1 reaction.

indeterminate or lepromatous leprosy (Table 2).

A total of 5 cases had Grade-II limb deformity in form of claw hand and ulcer. No cases of foot drop were observed. There was no case observed as nasal flattening or ocular manifestation. There was no bony pathology or limb amputation. The smear examination were negative in majority cases $(60.8 \%)$, however with increase in number of skin lesions per patient the chance of positivity of smear increased significantly $(<0.001)$, as shown in ( Table 3).

In two cases although bacteriological examination was negative, as diagnosis of leprosy was strongly suspected and skin biopsy was compatible with clinical diagnosis were included in the study. Out of 20 smear positive cases we had only 6 cases with BCG scar. (BCG scar is taken as BCG vaccination.) But the association between BCG vaccination and prevention of leprosy is not significant in our study $(p>0.05)$ (Table 4).

\section{Discussion}

Leprosy is widely prevalent in India. As age advances the number of lesions increased significantly $(p<0.005)$. This could be explained by long incubation period of the 
Table 2. Sex distribution according to type of pediatric leprosy cases $(\mathbf{N}-\mathbf{5 1})$.

\begin{tabular}{cccc}
\hline Type of cases & $\begin{array}{c}\text { Male (\%) } \\
\mathbf{N = \mathbf { 3 7 }}\end{array}$ & $\begin{array}{c}\text { Female (\%) } \\
\mathbf{N = \mathbf { 1 4 }}\end{array}$ & $\begin{array}{c}\text { Total (\%) } \\
\mathbf{N}=\mathbf{5 1}\end{array}$ \\
\hline TT & 00 & 3.92 & 3.92 \\
BT & 52.94 & 19.6 & 72.54 \\
BT (Type-1) & 7.8 & 00 & 7.8 \\
BB & 00 & 3.92 & 3.92 \\
BL & 3.92 & 00 & 3.92 \\
BL (Type-2) & 7.8 & 00 & 7.8 \\
Total & 72.54 & 27.45 & 100 \\
\hline
\end{tabular}

TT - Tuberculoid Leprosy, BT - Borderline Leprosy, BB - Borderline Borderline, BL - Borderline leprosy.

Table 3. Number of skin smear positive lesion at the time of presentation ( $\mathbf{N}-\mathbf{5 1})$.

\begin{tabular}{cccc}
\hline \multirow{2}{*}{$\begin{array}{c}\text { Number of skin } \\
\text { lesions }\end{array}$} & \multicolumn{2}{c}{ Result of skin smear } & \multirow{2}{*}{ Total } \\
\cline { 2 - 3 } & (+ve) (\%) & $(-\mathbf{v e})(\%)$ & \\
\hline $\mathbf{1}$ & 11.76 & 49.00 & 60.76 \\
$\mathbf{2}-\mathbf{1 0}$ & 11.76 & 7.80 & 19.56 \\
$>\mathbf{1 0}$ & 15.60 & 3.92 & 19.56 \\
Total & 39.20 & 60.78 & 100 \\
\hline
\end{tabular}

Table 4. Skin smear status in beg vaccinated children (N 51).

\begin{tabular}{cccc}
\hline BCG Scar & Smear (+ve) (\%) & Smear (-ve) (\%) & Total (\%) \\
\hline Positive & 11.76 & 29.40 & 41.17 \\
Negative & 27.45 & 31.30 & 58.82 \\
Total & 39.21 & 60.78 & 100 \\
\hline
\end{tabular}

disease. $59 \%$ cases occurred in the age group of $11-14$ yrs, as with other studies [9-11]. Males with the mean age of presentation were $10.3 \mathrm{yrs}$. and females at $10.7 \mathrm{yrs}$. Given a long incubation period it can be inferred that, younger children are indeed at the greatest risk [9]. The sex difference is greater in adults than in children [12]. we observed a male preponderance with male to female ratio of $2.64: 1$ and males comprise $72.54 \%$ of total cases. Similar observations were made by other studies [13]. Higher proportion among males was also observed by Dayal R [9]. This may be due to their greater mobility and increased opportunities for contact [14,15]. Moreover, detection in girls may possibly be lower than boys due to neglect of the female child.

In our study most common presentation was single hypo pigmented macular lesion comparable with several studies $[9,10]$. Selvasekhar A reported, $83 \%$ of the chil- dren had a single patch, though Vara N [16] reported single skin lesion in only $13.4 \%$ cases which is contrary to our observation. Eighty five percent cases had lesions over the exposed part of the body possibly due to direct inoculation of organisms into the skin. Similar observation has been made by other authors $[9,11]$. However Roy $\mathrm{R}$ et al. had more lesions over the covered areas [17].

Majority of children (56.8\%) presented from 6 month to $1 \mathrm{yr}$ after the onset of the disease and belongs to rural society $[18,19]$, signifies it needs more public awareness, regarding the disease. A study conducted by A. Singal et al. had duration of symptoms ranged from 2 months to 5 years. In $73 \%$ the duration was under one year [20]. About twelve percent had contact history positive inside the family which is close to the observation made by Vara $\mathrm{N}$ [16]. The lower incidence of contact might be due to missing information. In our study borderline tuberculoid was more common which is comparable with recent studies done by A. singal [20], VP shetty [21] (Table 1). Commonest type of leprosy was borderline tuberculoid similar to other studies $[9,11]$. This suggests that paucibacillary skin lesions were the dominant type of lesion and action for early diagnosis could be effective.

Type-1 reactions were observed in 4 cases and steroid was given along with multidrug therapy. Type-II reactions were observed in 4 cases. Lepromatous leprosy, pure neuritic and intermediate cases were not seen. Peripheral nerve involvement as thickened and/or tender was observed in only $27.4 \%$ cases in our study, other authors detected higher percentage $(70.1 \%)$ of peripheral nerve involvement $[9,16,17]$. We had Grade II deformities among $9.8 \%$ of our cases in the form of claw hands and ulcer. In recent study by A. Singal found that $12.8 \%$ of deformities [18]. Vara $\mathrm{N}$ observed Grade-II deformities in $10 \%$ of cases [16].

\section{Smear Positivity and BCG Scar}

In our study, smear examination was positive in $39.2 \%$ of cases which is higher than $19.8 \%$ as found in the study conducted by A. Singal. The positivity of the smear increases significantly $(p<0.001)$ with increase in number of skin lesions per patient. This is similar to observation made by Dayal R [9]. This could be inferred that bacillary load increases when the number of skin lesion increases over the body. The proportions of smear positive cases were less in number in scar positive patients as compared to scar negative patients. In our study there were no significant $(p>0.1)$ difference of leprosy in BCG scar positive and negative individuals. However the proportion of smear positive cases among the BCG scar negative individuals was higher than that of $\mathrm{BCG}$ scar positive individuals. There is now considerable evidence that $\mathrm{BCG}$ vaccination can provide some protection against 
leprosy [22]. This observation suggest to postulate that though BCG is not protective totally, it may at least attenuate the pathogenicity and modulates the immunestatus of the patients that foretell the high occurrence of paucibacillary leprosy in BCG scar positive children. A recent study showed increase in multibacillary cases $51.7 \%$ in A.singal [20] and 38\% in VP shetty [21], but in our study multi bacillary leprosy were only $15.6 \%$ of total cases. The study conducted by Dayal R also had less multibacillary cases [9]. Multibacillary cases were found in $10-14$ yrs of age indicates multibacillary cases may prevalent in latter part of the childhood.

\section{Conclusion}

An active surveillance is needed to identify the undetected hidden leprosy cases. Leprosy in children is essentially a disease of school age children, suggesting school survey as a tool for early detection and to prevent disabilities. Borderline tuberculoid is the dominant variety of presentation which responds to therapy. Early detection and effective treatment of leprosy patients in the pediatric age group can prevent the development of more severe devastating or crippling adult form of the disease.

\section{Limitations}

As this is a hospital based study, the results may not reflect the status childhood leprosy in a community. A rural community based study would reflect the real scenario. Sample size for the comparison of BCG and prevention of leprosy should be large.

\section{Contributions}

LD \& NBD drafted the initial manuscript and also engaged in management of patients. BKM, DDP and PS reviewed the literature, $\mathrm{LD} \& \mathrm{BKM}$ was responsible for designing the article, revision of manuscript and would act as the guarantor for the paper. JM \& NBD was involved in doing skin biopsy.

\section{Acknowledgements}

The authors are grateful to the Superintendent, S.C.B. medical college Cuttack for permitting them to publish the study.

\section{REFERENCES}

[1] P. K. Leprosy, "Text Book of Preventive and Social Medicine," 19th Edition, M/S Banarasi Das bhanot, Jabalpur, pp. 264-278.

[2] World Health Organization, "Global Burden of Leprosy at the End of 2010," The Weekly Epidemiological Record, Vol. 86, 2011, pp. 389-400.

[3] WHO, "Weekly Epidemiological Record," No. 28, 2000.
[4] M. B. Disability and Child Proportion, "Epidemiological Significance and Interpretation. National Leprosy Eradication Program Guidelines.” http://nlep.nic.in/guide.html

[5] F. J. Moet, R. P. Schuring, D. Pahan, L. Oskam and J. H. Richardus, "The Prevalence of Previously Undiagnosed Leprosy in the General Population of Northwest Bangladesh," PLOS Neglected Tropical Diseases, Vol. 2, 2008, p. e198. http://dx.doi.org/10.1371/journal.pntd.0000198

[6] S. Mahajan, K. Sardana, P. Bhushan, R. V. Koranne and V. Mendiratta, "A Study of Leprosy in Children, from a Tertiary Pediatric Hospital in India," Leprosy Review, Vol. 77, 2006, pp. 160-162.

[7] W. H. Jopling, "Hand Book of Leprosy," 3rd Edition, William-Heinemann, London, 1984.

[8] Dharmendra, "Leprosy," Sammat and Company, Bombay, 1985.

[9] R. Dayal, A. K. Paliwal, R. Prasad, et al., "A ClinicoBacteriological Profile of Leprosy in Children," Indian Paediatric, Vol. 26, 1989, pp. 122-128.

[10] R. Dayal, P. K. Agarwal, K. Katra, et al., "Diagnostic Value of Gene Probes and Its Co-Relation with Clinical Profile of Leprosy in Children," Indian Pediatrics, Vol. 31, 1994, pp. 1521-1527.

[11] A. Selvasekhar, J. Geetha, K. Nisha, N. Manimozhi, K. Jesudas and P. S. Rao, "Childhood Leprosy in an Endemic Area," Leprosy Review, Vol. 70, No. 1, 1999, pp. 21-27.

[12] R. Dayal, "Leprosy in Childhood," Recent Advances in Pediatrics, Vol. 1, 1991, p. 258.

[13] V. N. Sehgal and A. N. Chaudhary, "Leprosy in Children, A Prospective Study," 1993.

[14] C. Grover, S. Nanda, V. K. Garg and B. S. Reddy, "An Epidemiologic Study of Childhood Leprosy from Delhi," Pediatric Dermatology, Vol. 22, 2005, pp. 489-490. http://dx.doi.org/10.1111/j.1525-1470.2005.00124.x

[15] I. Kaur, S. Kaur, V. K. Sharma and B. Kumar, "Childhood Leprosy in Northern India," Pediatric Dermatology, Vol. 8, 1991, pp. 21-24. http://dx.doi.org/10.1111/j.1525-1470.1991.tb00833.x

[16] N. Vara, "Profile of New Cases of Childhood Leprosy in a Hospital Setting," Indian Journal of Leprosy, Vol. 78, No. 3, 2006, pp. 17-22.

[17] R. Roy and G. Kalla, "Pattern of Leprosy in Children in Jodhpur," Indian Journal of Leprosy, Vol. 69, No. 2, 1997, pp. 199-200.

[18] Van Braket Wh, et al., "Leprosy Review," Vol. 63, 1992, pp. 231-235.

[19] B. S. Bhavasar and N. R. Meheta, "An Epidemiological of Leprosy through School Survey in Surat Dist. (SouthGujurat)," Leprosy in India, Vol. 52, 1980, pp. 548-546.

[20] A. Singal, S. Sonthalia and D. Pandhi, "Childhood Leprosy in a Tertiary-Care Hospital in Delhi, India: A Reappraisal in the Post-Elimination Era," Leprosy Review, Vol. 82, 2011, pp. 259-269.

[21] V. P. Shetty, S. D. Ghate, A. V. Wakade, D. V. Thakur, U. H. Thakar and E. D'souza, "Clinical, Bacteriological, and Histopathological Characteristics of Newly Detected Chil- 
dren with Leprosy: A Population Based Study in a Defined Rural and Urban Area of Maharashtra, Western India," Indian Journal of Dermatology, Venerology, Lepro- logy, Vol. 79, No. 4, pp. 512-519.

[22] WHO, “Technical Report Series," 1988, p. 768. 